Fluency and confidence predict paramedic diagnostic intuition: An experimental study of applied dual-process theory

\author{
Toby Keene \\ https://orcid.org/0000-0002-6030-5151 \\ The Australian National University \\ Kristen Pammer \\ https://orcid.org/0000-0002-3183-5268 \\ University of Newcastle \\ Bill Lord \\ https://orcid.org/0000-0001-8821-5353 \\ Monash University \\ Carol Shipp \\ https://orcid.org/0000-0002-7586-3762 \\ Australian Capital Territory Ambulance Service
}

\begin{abstract}
Author Note
This research is supported by an Australian Government Research Training Program Scholarship.
\end{abstract}

Correspondence concerning this article should be addressed to Toby Keene, Research School of Psychology, The Australian National University, Acton, ACT, Australia, 2600. Contact: Toby.keene@anu.edu.au 


\title{
Fluency and confidence predict paramedic diagnostic intuition: An experimental study of applied dual-process theory
}

\begin{abstract}
Introduction. Paramedics care for the sick and injured in a variety of settings and have been observed to form an impression of their patient prior to meeting them based on limited information. We report an experiment using Australian paramedics $(n=64)$ and Australian paramedicine undergraduates $(n=44)$, which considered the processes underlying the formation of an intuitive diagnostic impression. Previous research has signalled roles for objective likelihood of the disease, subjective typicality of the disease, and the ease with which the impression comes to mind (answer fluency) as important in impression formation.

Method. Participants completed four brief written clinical vignettes under time pressure and with a concurrent navigation task to simulate conditions faced by paramedics prior to meeting a patient. The vignettes varied the objective likelihood of a diagnosis of Acute Coronary Syndrome (ACS), a condition often encountered by paramedics characterised by ambiguity and a need for accuracy. Diagnostic impression, confidence and subjective typicality of the vignette were self-reported while answer fluency was measured.
\end{abstract}

Results. Likelihood, answer fluency, self-reported typicality and confidence predicted the impression but there was no effect of experience. Students and experienced paramedics had comparable accuracy and performance.

Conclusion. The results support a role for answer fluency and confidence in forming that impression. We have shown it is possible to experimentally manipulate various factors associated with paramedic diagnostic impressions. These experimental methods can form the basis for additional studies into paramedic decision making.

Keywords: paramedic, emergency medical services, decision making, diagnosis, dual process theory, fuzzy trace theory 


\section{Introduction}

Paramedics provide care in a range of settings, most commonly in the community and away from structured clinical environments. Accurate paramedic diagnosis has been shown to improve patient outcomes for a number of conditions, whereas inaccurate or delayed paramedic diagnosis can result in errors or patient harm (1-7). Consequently, there is growing research interest in paramedics' ability to accurately diagnose various disease conditions and make appropriate treatment decisions $(8,9)$. This paper reports the results of the first in a series of experimental studies that aim to better understand paramedic diagnostic decisions.

There have been few previous studies of how paramedics make a diagnostic decision, all of them qualitative or survey designs (10-17). These studies identified common themes of rapid, sub-conscious "intuition" or "gut feelings" alongside conscious deliberative decisions (18). Paramedics were observed to form a rapid "impression" of what was wrong with the patient, that was subsequently revised using uncertainty reduction strategies, mostly explicit information gathering, $(10,11)$.

Several studies have identified that paramedics form an impression of their patient based on pre-arrival (often referred to as dispatch) information (17,19-21). A large multi-method study from the United Kingdom considered the effect of prearrival information on paramedic decisions (16) and concluded "Information conveyed to crews when dispatched to calls had the potential to inform and frame crew expectations, but this information was often limited and potentially misleading." (p. 50) However, the factors driving the formation of an impression under these conditions have not been explicitly researched to date. This study seeks to better understand the formation of this intuitive impression based solely on limited prearrival information, such as a paramedic would receive en route to a patient. Future studies will investigate the effect of the impression on subsequent diagnostic decision making.

\section{Dual process decision-making}

Dual Process Theories (DPT) argue that people broadly use two cognitive processes to form judgements and make decisions. Type 1 processes are classically described as fast, intuitive, affective and automatic, and align to common descriptions of "intuition" or "gut feeling". Type 2 processes are classically slower, 
deliberative, and verbal. It is generally agreed that a Type 1 intuitive impression is formed by matching the current situation with established cognitive prototypes, though there are competing views about how this works (22-24).

Fast-and-frugal heuristic paradigms argue prototypes are built and retrieved through knowledge and experience of the objective environment, for simplicity referred to here as 'likelihood' (24). Likelihood can be determined statistically, based on reported cases and epidemiological analysis; it is independent of personal experience. Likelihood exists on a continuum; for example, a patient with facial droop and unilateral arm weakness is likely having a stroke and unlikely to have acute asthma, regardless of the paramedic's subjective experience of patients with these signs.

An alternative conception of intuition, Fuzzy Trace Theory (25) argues that people encode and retrieve cognitive representations based on an individual's subjective evaluation of the situation, which may or may not reflect the objective likelihood. 'Typicality' is defined here as the individual's subjective representation of specific cues being associated with a disease. In other words, how typical is a patient relative to others with the same disease in the eyes of the paramedic? There is growing evidence that clinicians make decisions consistent with Fuzzy Trace Theory, but it has not been previously researched in paramedics (26).

The interaction between Type 1 and Type 2 processes has been studied by Thompson and colleagues (27) who argued that the outcome of a Type 1 process is accompanied by a subjective 'feeling of rightness' that guides the degree to which Type 2 processes engage to update or overrule an initial Type 1 judgement. Feeling of rightness, which could be alternatively conceived as 'confidence', is theorised to be formed primarily by the ease with which the impression comes to mind, known as answer fluency (28). Answer fluency and 'feeling of rightness' have experimental support in laboratory settings (29) but have not been assessed using clinical problems, so their role in the formation of intuition in paramedics is unknown.

This study considers the effect of varying likelihood, typicality, and answer fluency on the diagnostic impression formed under circumstances designed to replicate the work process of paramedics. The lack of prior experimental research on paramedic decision-making means this research is somewhat exploratory. However, a number of specific research questions are presented for this study: 
R1: What are the relationships between likelihood, typicality, answer fluency, and confidence?

R2: Which of the study variables predict paramedic impression?

$R 3:$ What is the relationship between the study variables and paramedic experience?

\section{Method}

\section{Participants}

Participants were practicing paramedics employed by an Australian government ambulance service and undergraduate paramedicine students studying an accredited paramedicine degree at an Australian university. Sixty-four paramedics and forty-four students participated (see Table 1). Paramedics were invited to participate in the study during a regularly scheduled employer in-service program by the researcher or research assistant. Students were invited to participate during a routinely scheduled class. No inducements or payments were offered for participation.

\begin{tabular}{|c|c|c|c|c|}
\hline Group & n (\%) & $\begin{array}{c}\text { Age } \\
\text { (median; IQR, } \\
\text { years) }\end{array}$ & Gender (n;\%) & $\begin{array}{l}\text { Years of experience } \\
\text { (median; IQR) }\end{array}$ \\
\hline \multirow[t]{2}{*}{ Paramedics } & $\begin{array}{c}64 \\
(59 \%)\end{array}$ & $42(32-49)$ & $\begin{array}{c}\text { Female: } 22 \\
(34 \%) \\
\text { Male: } 41 \\
(66 \%) \\
\end{array}$ & $13(6-21)$ \\
\hline & & & & Year of study \\
\hline Students & $\begin{array}{c}44 \\
(41 \%)\end{array}$ & $21(20-22)$ & $\begin{array}{c}\text { Female: } 26 \\
(59 \%) \\
\text { Male: } 18 \\
(41 \%)\end{array}$ & $\begin{array}{c}2^{\text {nd }} \text { year: } 16 \\
3^{\text {rd }} \text { year (single degree): } \\
14 \\
4^{\text {th }} \text { year (combined } \\
\text { degree): } 14\end{array}$ \\
\hline
\end{tabular}

\section{Design}

This study used a repeated-measures experimental design that manipulated four levels of likelihood and measured self-reports of typicality and confidence on five-point ordinal scales and impression as a forced choice from four pre-defined 
options. Answer fluency was measured as the response time for the impression; timing commenced from when the options were presented and stopped with the participant's first recorded impression. The experiment aimed to induce an intuitive decision by placing participants under time pressure and by undertaking an unrelated concurrent task $(27,30)$.

The experiment was designed to simulate part of the normal paramedic work process. Typically, a paramedic's first exposure to a patient occurs before they meet. In many countries, members of the public requesting paramedic attendance in an emergency do so via a centralised call centre (e.g. 000 in Australia, 911 in the USA). Call centre staff seek basic information about the location and nature of the request, including limited patient information. This information is passed to the attending paramedic verbally or electronically before, or en route to the patient. This allows the paramedic to form an "impression" of what might be wrong with the patient before ever seeing them, often while concurrently performing other tasks, such as navigating and driving to the location. When the paramedic arrives at the patient's location, they can begin a more comprehensive and structured assessment.

\section{Ethical review}

The study protocol was considered and approved by the Australian National University Human Research Ethics Committee (2017/141) and the Australian Catholic University Human Research Ethics Committee (2017-163R). All experimental materials were linked to the participant consent forms using a unique code, known only to participants. This process was approved by the ethics committees to allow participants to withdraw their involvement after data was collected without the researchers being able to identify individual responses. No participant exercised this option. The researchers were unable to link responses back to individual participants. There were no consequences to participants based on their responses to the study.

\section{Materials}

One area of paramedic practice where there is good knowledge of objective likelihood is Acute Coronary Syndrome (ACS). The signs and symptoms of ACS 
have been studied in several retrospective case-series, with likelihood ratios derived for various signs and symptoms (31-34). From these, four written vignettes were designed to show a progression from most likely to least likely to be ACS based on the published likelihood ratios (Table 2). The information provided was deliberately restricted to a few key points similar to what paramedics would receive en route to an emergency incident.

The experimental materials were presented on Qualtrics survey software (Qualtrics, Provo, UT). Paramedics accessed the software using a 10-inch touchscreen tablet in the classroom, while students used a desktop computer located in a university computer lab. Participants interacted with the software using a touch screen (with their finger or a stylus) or a mouse. Paramedics completed the experiment individually in a classroom environment ranging in size from two to 12 . The paramedicine students participated individually in class groups of 20-30. The survey was facilitated by a researcher or research assistant. The facilitator read prescripted instructions and had no knowledge of participant responses.

Table 2.

Experimental Stimuli.

\begin{tabular}{|c|c|}
\hline Likelihood & Stimulus \\
\hline $\begin{array}{l}\text { Most Likely }(L R+2.1- \\
6.4)\end{array}$ & $\begin{array}{l}\text { You are dispatched to a patient with chest pain radiating to } \\
\text { both arms. The pain is similar to a previous heart attack. } \\
\text { The patient has coronary artery disease, hypotension and } \\
\text { is vomiting. }\end{array}$ \\
\hline Likely (LR+1.5-2) & $\begin{array}{l}\text { You are dispatched to a patient with chest pain radiating to } \\
\text { the neck that is worse with exertion. The patient } \\
\text { is breathing rapidly and has a history of a previous heart } \\
\text { attack and cerebrovascular disease. }\end{array}$ \\
\hline $\begin{array}{l}\text { Less Likely (LR+ 1.1- } \\
\text { 1.3) }\end{array}$ & $\begin{array}{l}\text { You are dispatched to a patient with chest pain described } \\
\text { as "burning" and radiating to the left arm. The patient } \\
\text { is short of breath and sweating. The patient has a history of } \\
\text { high cholesterol. }\end{array}$ \\
\hline $\begin{array}{l}\text { Least } \\
\text { Likely }(L R+0.1-1)\end{array}$ & $\begin{array}{l}\text { You are dispatched to a patient with chest } \\
\text { pain that changes with their posture and breathing. The } \\
\text { patient has history of obesity and diabetes. The patient is } \\
\text { complaining of palpitations. }\end{array}$ \\
\hline
\end{tabular}

Note. Cues are underlined here for clarity; they were not highlighted to the participants. (LR+: positive likelihood ratio) 


\section{Procedure}

After providing consent, participants undertook six practice tasks following onscreen instructions. Each of the first three practice tasks displayed an image of a street map with two markers on it. Participants were instructed to mark a route between the markers. To ensure consistent task difficulty in both practice and experimental tasks, the markers were approximately the same linear distance apart and required a similar number of turns in the optimal route. The map appeared on the screen for only 12 seconds before automatically advancing, regardless of whether the full route had been marked or not.

There is no standard experimental method for inducing an intuitive response. The strategy employed here was based on previous research (27) that used time pressure and attention-demanding secondary tasks (30) to induce intuitive responses to problems with predictable answers. Both studies employed these strategies on well-studied phenomena such as base-rate neglect and logical syllogisms; this method has not been used on clinical reasoning problems to our knowledge. The nature of the secondary task was chosen with ecological validity in mind; paramedics routinely receive pre-arrival information either concurrent with or immediately prior to navigation and driving tasks.

The first three practice tasks consisted of the navigation exercise only; the second three practice tasks combined the navigation exercise with clinical information. For these tasks, at the top of the map was brief written clinical information similar to that seen by paramedics when traveling to a patient . Figure 1 shows an example of the navigation task, combined with the clinical information. The word length of each vignette was similar, as were the number of cues. Again, the participant had only 12 seconds to complete the task and read the information provided.

Following the navigation task, participants were asked the following questions (possible responses in square brackets):

1. Thinking just about the pre-arrival information, what do you think is most likely to be wrong with the patient? (Choose one option) [Presented in random order: Acute Coronary Syndrome; Respiratory Tract Infection; Musculoskeletal injury; Pulmonary embolism] 
2. For the previous question, you chose [response to previous question]. Based on the pre-arrival information you saw, how confident are you about your answer? [Not at all confident; Low confidence; Confident; Very confident]

3. Based just on the pre-arrival information you saw, how representative or typical was that patient compared to others with [response to first question] you know about or have experienced? [Very atypical; Atypical; Neither typical nor atypical; Typical; Very Typical]

Responses to question one are referred to below as 'impression'; responses to questions two and three are referred to as 'confidence' and 'typicality', respectively. Following the six practice tasks, participants were presented with the four experimental tasks in random order. The experimental tasks appeared to the participant as identical to the last three practice tasks. Figure 2 outlines the experimental procedure. Note that Acute Coronary Syndrome was not mentioned at all in the instructions to participants, nor highlighted in the materials to avoid the potential of drawing attention to this response option. 


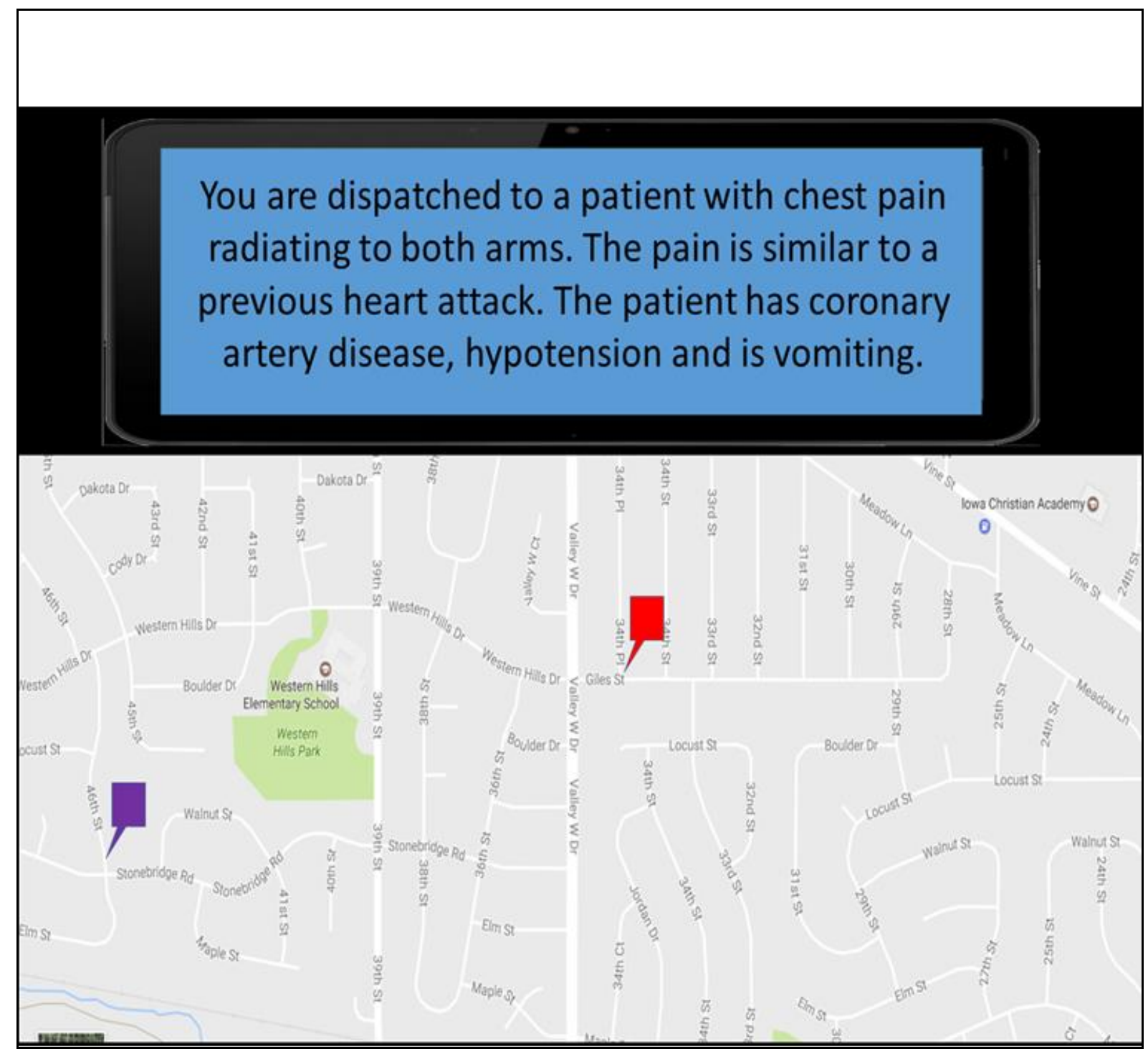

Figure 1. Example of the stimulus material provided to participants. 


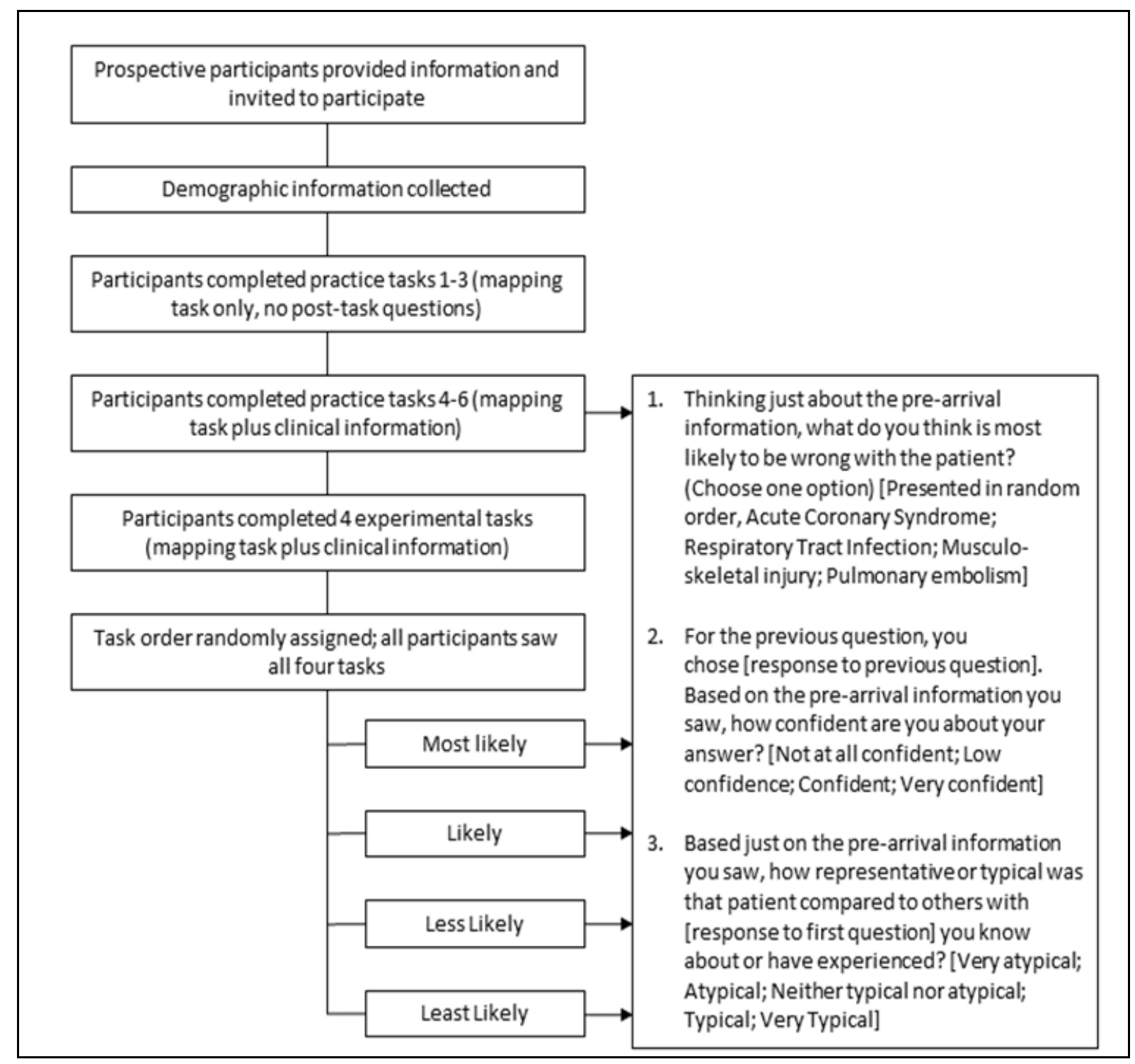

Figure 2. Summary of experimental procedure.

\section{Statistical Analysis}

Statistical analysis was conducted using 'R' version 3.4.2 (35). Frequency data are reported as count, proportion $(95 \% \mathrm{Cl})$. Continuous variables are reported as median (IQR). Comparisons of categorical data were conducted using Fisher's Exact Test and continuous variables were compared using the relevant non-parametric test with P-values set at .05 two-tailed. Correlations were calculated using the "rmcorr" $\mathrm{R}$ package (36) for repeated-measures correlations. To consider the role of experience, the paramedic group was divided according to the median: Less experienced ( $<13$ years) and More Experienced ( $>=13$ years). The raw data is available under Creative Commons License at: DOI 10.25911/5e701e8946cd8. 
Linear mixed models are an extension of simple linear models that allow for both fixed and random effects. They also allow for within-group and between-group analysis from the same data and are increasingly used for modelling nonindependent data sets $(37,38)$. The effects of the measured variables (likelihood, confidence, answer fluency, and typicality) on participants' impression were examined using participant as a random effect and the other predictors as fixed effects. The navigation task was assessed by the number of points participants added to their route selection. Impression was modelled as a dichotomous variable (ACS vs non-ACS). The first model included all the predictor variables with nonsignificant predictors removed stepwise. Models were compared using ANOVA with chi-square to determine differences (39). Models were also generated to determine the presence of an interaction between experience and the other predictors.

Reported below are the results for those models that showed best fit.

\section{Results}

\section{R1: What are the relationships between likelihood, typicality, answer fluency, and confidence?}

Repeated-measures correlations showed strong correlations between study variables (Table 3). Typicality had a negative relationship with answer fluency increasing from 3.02 seconds (IQR 1.84) in vignettes rated as very typical to 9.96 seconds (IQR 12.31) in atypical vignettes (Kruskal-Wallis chi-squared $=61.146, \mathrm{df}=$ $3 ; p<.001$; Figure 3$)$.

Table 3.

Correlations between study variables

\begin{tabular}{lccc}
\hline & Likelihood & Answer Fluency & Typicality \\
Answer Fluency & $-.294^{* * *}$ & & \\
Typicality & $.358^{* * *}$ & $-.388^{* * *}$ & \\
Confidence & $.435^{* * *}$ & $-.408^{* * *}$ & $.736^{* * *}$ \\
\hline Note. ${ }^{* \star *} \mathrm{p}<.001$ & & & \\
\hline
\end{tabular}




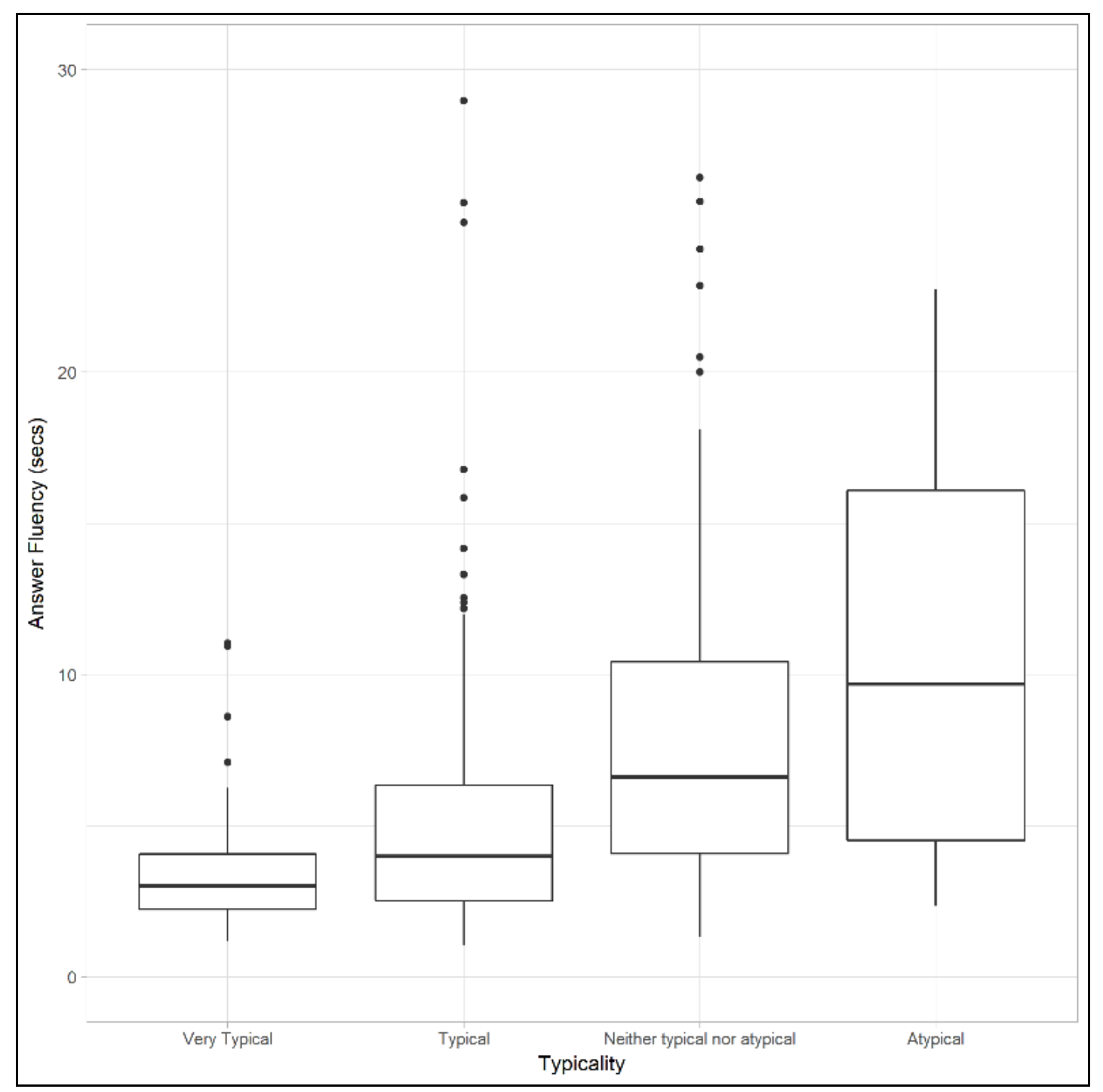

Figure 3. Answer fluency (seconds) by typicality.

\section{R2: Which of the study variables predict paramedic impression?}

Using linear mixed modelling as outlined above, likelihood, typicality, confidence and answer fluency significantly predicted an impression of ACS when other variable were controlled for (Table 4). The remaining variables were not predictive, but removing them did not improve the overall fit of the model. The significant predictors were examined individually to consider their role. 


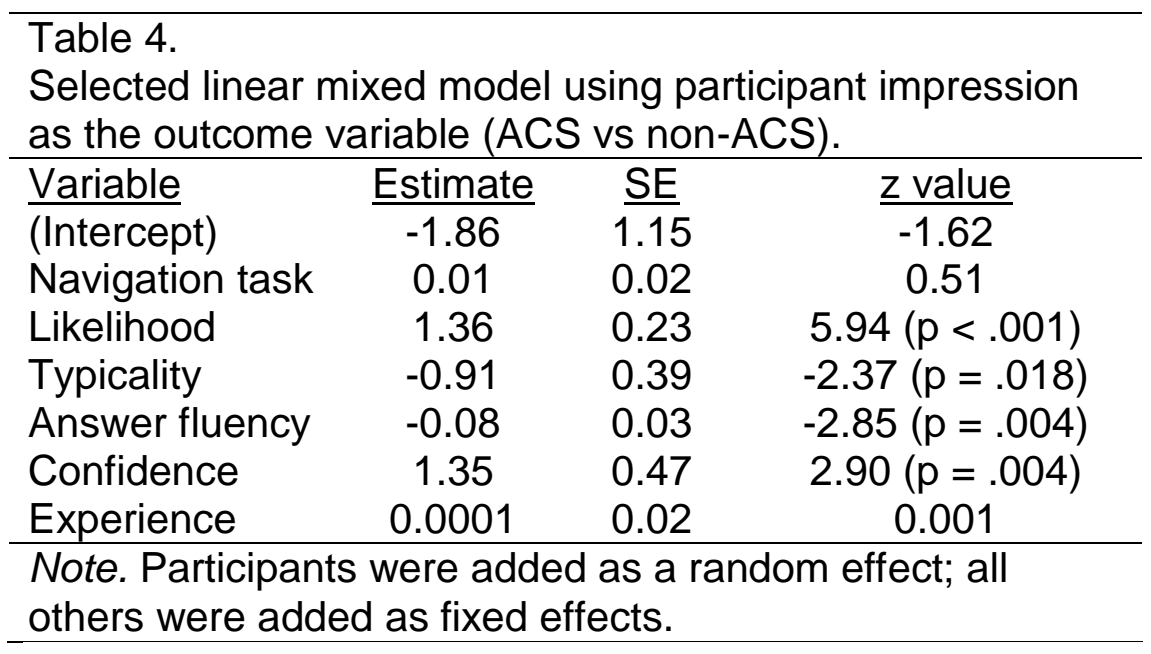

Overall, likelihood predicted impression when vignettes were clearly very likely or very unlikely but relatively more ambiguous presentations showed the reverse relationship. The proportion of participants with impression of ACS declined from .94 (95\% Cl: .88, .98) in the Most Likely condition to .24 (95\% Cl: .17, .33) in the Least Likely condition (95\%Cl: 20.05, 162.22; $\mathrm{p}<0.001$; Table 5). However, more participants chose ACS in the Less Likely $(.88 ; 95 \% \mathrm{Cl}: .80, .93)$ condition than in the Likely (.76; 95\%Cl: .67, .83) conditions (95\%Cl: 0.20, 0.98; $\mathrm{p}=.03)$.

Participants tended to be confident in their impression across all conditions; overall $65 \%$ of impressions were rated confident or very confident (Table 6). Only six vignettes (1.4\%) resulted in impressions that participants were not at all confident in, roughly evenly distributed across all likelihood conditions. Overall, the trend was for increasing impression of ACS with increasing confidence $(95 \% \mathrm{Cl}: 0.11,0.29 ; \mathrm{p}<$ .001). The same pattern was found for typicality, as expected given the strong correlation between confidence and typicality. Similarly, participant responses were more fluent for impression of ACS compared to other impressions (median: 3.84 (3.66) seconds vs 7.88 (6.25); $\mathrm{W}=9542.5, \mathrm{p}<.001)$. 
Table 5.

Proportion $(95 \% \mathrm{Cl})$ of participants with impression of ACS by likelihood and experience.

\begin{tabular}{lllll}
\hline & Most Likely & Likely & $\underline{\text { Less Likely }}$ & $\frac{\text { Least Likely }}{\text { All participants }}$ \\
\cline { 2 - 5 } & $.94(.88, .98)$ & $.76(.67, .83)$ & $.88(.80, .93)$ & $.24(.17, .33)$ \\
Students & $.93(.80, .98)$ & $.77(.62, .88)$ & $.86(.72, .94)$ & $.27(.16, .43)$ \\
Less Experienced & $1(.86,1)$ & $.81(.62, .92)$ & $.87(.69, .96)$ & $.16(.06, .35)$ \\
$\begin{array}{l}\text { paramedics }(<13 \\
\text { years })\end{array}$ & & & & \\
$\begin{array}{l}\text { More Experienced } \\
\text { paramedics }\end{array}$ & $.91(.75, .98)$ & $.70(.51, .84)$ & $.91(.75, .98)$ & $.27(.14, .46)$ \\
$(>=13$ years $)$ & & & & \\
\hline
\end{tabular}

Table 6.

Frequency and proportion $(95 \% \mathrm{Cl})$ of participants with impression of ACS by confidence and typicality.

\begin{tabular}{cccccccc}
\hline $\mathrm{n}$ & $\begin{array}{c}\text { Proportion } \\
(95 \% \mathrm{Cl})\end{array}$ & $\mathrm{n}$ & $\begin{array}{c}\text { Proportion } \\
(95 \% \mathrm{Cl})\end{array}$ & $\mathrm{n}$ & $\begin{array}{c}\text { Proportion } \\
(95 \% \mathrm{Cl})\end{array}$ & $\mathrm{n}$ & $\begin{array}{c}\text { Proportion } \\
(95 \% \mathrm{Cl})\end{array}$ \\
\hline
\end{tabular}

\begin{tabular}{|c|c|c|c|c|c|c|c|}
\hline \multicolumn{8}{|c|}{ Confidence } \\
\hline \multicolumn{2}{|c|}{ Very confident } & \multicolumn{2}{|c|}{ Confident } & \multicolumn{2}{|c|}{ Low confidence } & \multicolumn{2}{|c|}{ Not at all confident } \\
\hline 45 & $.91(.78, .97)$ & 237 & $.82(.77, .87)$ & 143 & $.45(.37, .53)$ & & $.83(.37, .99)$ \\
\hline \multicolumn{8}{|c|}{ Typicality } \\
\hline \multicolumn{3}{|c|}{ Very Typical } & Typical & \multicolumn{2}{|c|}{$\begin{array}{l}\text { Neither typical nor } \\
\text { atypical }\end{array}$} & & Atypical \\
\hline 39 & $.92(.78, .98)$ & 222 & $.79(.73, .84)$ & 144 & $.52(.44, .60)$ & 26 & $.69(.48, .85)$ \\
\hline
\end{tabular}

\section{R3: What is the relationship between the study variables and paramedic experience?}

There was no effect of experience for students, less experienced paramedics and more experienced paramedics. None of the generated models showed any effect for years of experience when treated as an ordinal variable. The models were recalculated with experience as a continuous variable. It still had no effect.

\section{Discussion}


Previous research has observed paramedics form a rapid impression of a patient's condition based on limited information $(10,11)$. Such impressions have been linked to bias leading to diagnostic error in medical professions (40), so a greater understanding of impression formation may lead to a greater understanding of bias. This experiment studied the impression formed by practicing paramedics and undergraduate paramedicine students on simulated patients with varying likelihood of having ACS. Objective likelihood, answer fluency, subjective typicality and confidence all independently predicted impression of ACS, but there was no effect of paramedic experience.

Extremes of likelihood behaved as predicted with $94 \%$ of participants forming an impression of ACS in the most objectively likely condition and $26 \%$ in the least objectively likely condition, showing good impression accuracy at the extremes. This was not so in the middle conditions with $76 \%$ choosing ACS in the Likely condition and $88 \%$ in the Less Likely condition. This shows a degree of over-diagnosis in more ambiguous presentations that may reflect risk aversion. ACS is a life-threatening emergency and can present atypically, so paramedics would be expected to exercise a degree of risk aversion in order to avoid a missed diagnosis of ACS. However, impressions of ACS in the Least Likely condition fell to chance levels (26\%), so participants were not simply selecting ACS in all conditions as the risk averse option.

We found answer fluency predicted impression, as did self-reported confidence and typicality. Thompson and colleagues (27) proposed that decision makers experience a "feeling of rightness" about the accuracy of their intuition. Here, confidence can be considered an alternate representation of feeling of rightness. The results here support Thompson et al's (27) theory in that answer fluency and confidence independently predicted impression. The effect of answer fluency and the impression on subsequent reasoning will be considered in future studies. Overall, confidence was high and strongly correlated with typicality, despite the distractions and relative paucity of information, suggesting participants were comfortable with forming and recording an impression in the face of limited information.

This was the first study we are aware of to compare the cognitive processes of undergraduate paramedicine students with practicing paramedics. In Australia today, qualification as a paramedic requires a three-year bachelor degree, though this is a relatively recent development. Undergraduate student participants were all in their $2^{\text {nd }}$ year or higher, with $86 \%$ in the final year of their degree. As such, all would have 
completed study on ACS and possibly encountered patients with ACS on clinical placements. Comparatively, paramedic participants in this study were highly experienced in their roles, with a median 13 years of experience. Despite this, there was no effect of experience on impression, nor an interaction between experience and any variable.

Competing theories of Type 1 processing offer different roles for experience. The lack of experience effects runs contrary to both fast-and-frugal and fuzzy trace explanations for intuition. Fast and frugal heuristics argue that intuitive decisions are based on knowledge of the statistical environment (24). If so, we expected to see an interaction between likelihood (which is derived from real-world epidemiological data) and experience. This did not occur; there was no effect of experience on impression once other variables were controlled. Alternatively, fuzzy trace theory proposes that as practitioners gain experience, they prefer decisions based on the gist - or bottom line meaning - of the situation (25). That is, experts rely predominantly on intuition, such that it strongly influences a subsequent final decision. The effects of the intuitive impression may be best seen by their impact on the considered final diagnosis. Future research will examine this possibility.

As with any experimental research, there are a number of limitations to be considered. Firstly, the vignettes were written. While written vignettes are commonly used throughout paramedic initial and ongoing education and assessment, they obviously lack fidelity compared to real situations. While the information provided was prepared and piloted by experienced paramedics to closely reflect the nature and content of information presented to paramedics in the field, there may have been some discrepancies. Secondly, the question order may have affected responses. Confidence and typicality were assessed after the impression was recorded. Participants may have revised their initial judgements of confidence and typicality in light of the impression they recorded. The study design had no way of determining this. Finally, impression relied upon a multiple choice response; participants may have chosen a different, more likely impression rather than the ones on offer.

\section{Conclusion}

To our knowledge, this is the first attempt to experimentally study clinical reasoning in paramedics. Previous observational studies have observed the 
formation of rapid intuitive impressions based on limited dispatch information, followed by a more considered final diagnosis. Here we have investigated the formation of intuitive impressions by considering fast-and-frugal, fuzzy trace and metacognitive theories. Participants in this study were highly accurate in their impressions when the vignettes were very likely or very unlikely to be ACS, with a degree of over-diagnosis in less likely presentations under conditions of time pressure and a concurrent task. We have shown it is possible to experimentally manipulate various factors associated with paramedic diagnostic decisions. These experimental methods can form the basis for additional studies into paramedic decision making. The results here argue strongly for a role for answer fluency and confidence in forming that impression, which may have an impact on subsequent diagnosis. The methods applied here may be used to understand these processes better and develop strategies to improve diagnostic reasoning in paramedics. 


\section{References}

1. Crocco TJ. Streamlining Stroke Care: From Symptom Onset to Emergency Department. J Emerg Med [Internet]. 2007 Oct [cited 2018 Jan 7];33(3):25560. Available from:

http://www.sciencedirect.com/science/article/pii/S0736467907001849

2. Gross BW, Dauterman KW, Moran MG, Kotler TS, Schnugg SJ, Rostykus PS, et al. An Approach to Shorten Time to Infarct Artery Patency in Patients With ST-Segment Elevation Myocardial Infarction. Am J Cardiol. 2007 May;99(10):1360-3.

3. Millar-Craig MW, Joy A V., Adamowicz M, Furber R, Thomas B. Reduction in treatment delay by paramedic ECG diagnosis of myocardial infarction with direct CCU admission. Hear London. 1997 Nov;78(5):456.

4. Mosley I, Nicol M, Donnan G, Patrick I, Kerr F, Dewey H. The Impact of Ambulance Practice on Acute Stroke Care. Stroke. 2007 Oct;38(10):2765-70.

5. Terkelsen CJ, Lassen JF, Nørgaard BL, Gerdes JC, Poulsen SH, Bendix K, et al. Reduction of treatment delay in patients with ST-elevation myocardial infarction: impact of pre-hospital diagnosis and direct referral to primary percutanous coronary intervention. Eur Heart J [Internet]. 2005 Apr [cited 2017 Dec 30];26(8):770-7. Available from:

https://academic.oup.com/eurheartj/article/26/8/770/2888078

6. Christie A, Costa-Scorse B, Nicholls M, Jones P, Howie G. Accuracy of working diagnosis by paramedics for patients presenting with dyspnoea. Emerg Med Australas [Internet]. 2016 Oct [cited 2017 Dec 30];28(5):525-30. Available from: http://onlinelibrary.wiley.com/doi/10.1111/17426723.12618/abstract

7. Williams T, Finn J, Fatovich D, Tohira H, Brink D, Perkins GD, et al. Predicting sepsis using prehospital data from the ambulance service: A linked data cohort study. Aust Crit Care [Internet]. 2016 May [cited 2016 Jun 9];29(2):119. Available from: http://inkinghub.elsevier.com/retrieve/pii/S1036731415001617

8. Wilson C, Harley C, Steels S. Systematic review and meta-analysis of prehospital diagnostic accuracy studies. Emerg Med J [Internet]. 2018 Sep 14 [cited 2018 Oct 10];35:757-64. Available from: http://www.ncbi.nlm.nih.gov/pubmed/30217952

9. Koivulahti O, Tommila M, Haavisto E. The accuracy of preliminary diagnoses made by paramedics - a cross-sectional comparative study. Scand J Trauma Resusc Emerg Med [Internet]. 2020 Jul 23 [cited 2020 Aug 2];28(1):70. Available from: https://pubmed.ncbi.nlm.nih.gov/32703267/

10. Alexander M. Reasoning Processes Used by Paramedics to Solve Clinical Problems [Internet]. George Washington University; 2010. Available from: http://media.proquest.com/media/pq/classic/doc/1957424741/fmt/ai/rep/NPDF ?_s=qvobOrydcqk5\%2Fy0jEitmAISTgts\%3D

11. Harenčárová H. Managing uncertainty in paramedics' decision making. J Cogn 
Eng Decis Mak [Internet]. 2017 Dec [cited 2017 Apr 19];11(1):42-62. Available from: http://journals.sagepub.com/doi/10.1177/1555343416674814

12. Jensen JL. Paramedic clinical decision making (Masters thesis). Dalhousie University; 2010.

13. Jensen JL, Bienkowski A, Travers AH, Calder LA, Walker M, Tavares W, et al. A survey to determine decision-making styles of working paramedics and student paramedics. Can J Emerg Med [Internet]. 2016 May 2 [cited 2016 May 8];18(3):213-22. Available from:

http://www.journals.cambridge.org/abstract_S1481803515000950

14. Jensen JL, Croskerry $\mathrm{P}$, Travers $\mathrm{AH}$. Consensus on paramedic clinical decisions during high-acuity emergency calls: results of a Canadian Delphi study. Can J Emerg Med. 2011 Sep;13(5):310-8.

15. Maclver K. Paramedic decision-making: Expert evaluation of a new decisionmaking model [A thesis presented in partial fulfilment of the requirements for the degree of Master of Professional Practice]. [Wellington, New Zealand]: Whitireia Community Polytechnic; 2017.

16. O'Hara R, Johnson M, Siriwardena AN, Weyman A, Turner J, Shaw D, et al. A qualitative study of systemic influences on paramedic decision making: care transitions and patient safety. J Health Serv Res Policy [Internet]. 2015 Jan [cited 2018 Jul 10];20:45-53. Available from:

http://journals.sagepub.com/doi/10.1177/1355819614558472

17. Reay G, Rankin JA, Smith-MacDonald L, Lazarenko GC. Creative adapting in a fluid environment: an explanatory model of paramedic decision making in the pre-hospital setting. BMC Emerg Med [Internet]. 2018;18(1):42. Available from: https://bmcemergmed.biomedcentral.com/articles/10.1186/s12873-018-0194-1

18. Perona M, Rahman MA, O’Meara P. Paramedic judgement, decision-making and cognitive processing: a review of the literature. Australas $\mathrm{J}$ Paramed [Internet]. 2019 Feb 4 [cited 2019 Feb 20];16(0). Available from: https://ajp.paramedics.org/index.php/ajp/article/view/586

19. Simpson P, Thomas R, Bendall J, Lord B, Lord S, Close J. 'Popping nana back into bed' - a qualitative exploration of paramedic decision making when caring for older people who have fallen. 2017;

20. Halter M, Vernon S, Snooks H, Porter A, Close J, Moore F, et al. Complexity of the decision-making process of ambulance staff for assessment and referral of older people who have fallen: a qualitative study. Emerg Med J EMJ. 2011 Jan;28(1):44-50.

21. Jones CMC, Cushman JT, Lerner EB, Fisher SG, Seplaki CL, Veazie PJ, et al. Prehospital Trauma Triage Decision-making: A Model of What Happens between the 9-1-1 Call and the Hospital. Prehospital Emerg Care [Internet]. 2016 Jan 2 [cited 2019 Feb 20];20(1):6-14. Available from: http://www.tandfonline.com/doi/full/10.3109/10903127.2015.1025157

22. Glöckner A, Witteman C. Beyond dual-process models: A categorisation of processes underlying intuitive judgement and decision making. Think Reason [Internet]. 2010 Feb [cited 2017 Dec 28];16(1):1-25. Available from: 
https://doi.org/10.1080/13546780903395748

23. Zsambok CE, Klein G. Naturalistic Decision Making - Caroline E. Zsambok, Gary Klein - Google Books. New York: Lawrence Erlbaum Associates; 1997.

24. Hafenbrädl S, Waeger D, Marewski JN, Gigerenzer G. Applied Decision Making With Fast-and-Frugal Heuristics. J Appl Res Mem Cogn [Internet]. 2016 Jun [cited 2017 Mar 15];5(2):215-31. Available from: http://linkinghub.elsevier.com/retrieve/pii/S2211368116300560

25. Corbin JC, Reyna VF, Weldon RB, Brainerd CJ. How reasoning, judgment, and decision making are colored by gist-based intuition: A fuzzy-trace theory approach. J Appl Res Mem Cogn [Internet]. 2015 Dec [cited 2018 Apr 24];4(4):344-55. Available from:

http://www.sciencedirect.com/science/article/pii/S2211368115000728

26. Blalock SJ, Reyna VF. Using fuzzy-trace theory to understand and improve health judgments, decisions, and behaviors: A literature review. Heal Psychol [Internet]. 2016 [cited 2018 Jun 10];35(8):781-92. Available from: http://doi.apa.org/getdoi.cfm?doi=10.1037/hea0000384

27. Thompson VA, Prowse Turner JA, Pennycook G. Intuition, reason, and metacognition. Cogn Psychol [Internet]. 2011 Nov 1 [cited 2018 Jul 30];63(3):107-40. Available from: https://www-sciencedirectcom.virtual.anu.edu.au/science/article/pii/S0010028511000454

28. Thompson VA, Turner JAP, Pennycook G, Ball LJ, Brack $H$, Ophir $Y$, et al. The role of answer fluency and perceptual fluency as metacognitive cues for initiating analytic thinking. 2013 [cited 2018 Dec 4]; Available from: http://dx.doi.org/10.1016/j.cognition.2012.09.012

29. Wang S, Thompson V. Fluency and Feeling of Rightness: The Effect of Anchoring and Models. Psychol Top [Internet]. 2019 [cited 2019 Dec 26];28:37-72. Available from: https://doi.org/10.31820/pt.28.1.3

30. De Neys W. Automatic-Heuristic and Executive-Analytic Processing during Reasoning: Chronometric and Dual-Task Considerations. Q J Exp Psychol [Internet]. 2006 Jun [cited 2019 Mar 4];59(6):1070-100. Available from: http://journals.sagepub.com/doi/10.1080/02724980543000123

31. Body R, Carley S, Wibberley C, McDowell G, Ferguson J, Mackway-Jones K. The value of symptoms and signs in the emergent diagnosis of acute coronary syndromes. Resuscitation [Internet]. 2010 Mar [cited 2017 Mar 28];81(3):2816. Available from:

http://linkinghub.elsevier.com/retrieve/pii/S0300957209005954

32. Colbeck M. Paramedic diagnosis of acute coronary syndrome in the out-ofhospital patient with acute, non-traumatic chest pain: The RSVP3 HEART exam. Australas J Paramed. 2016;13(4).

33. Fanaroff AC, Rymer JA, Goldstein SA, Simel DL, Newby LK. Does This Patient With Chest Pain Have Acute Coronary Syndrome? JAMA [Internet]. 2015 Nov 10 [cited 2017 Mar 28];314(18):1955. Available from:

http://jama.jamanetwork.com/article.aspx?doi=10.1001/jama.2015.12735 
34. Sharif S, Upadhye S. Does This Patient With Chest Pain Have Acute Coronary Syndrome? Ann Emerg Med [Internet]. 2016 Dec [cited 2017 Mar 28];

Available from: http://linkinghub.elsevier.com/retrieve/pii/S0196064416311982

35. R Core Team. R: A language and environment for statistical computing [Internet]. Vienna, Austria: R Foundation for Statistical Computing; 2017. Available from: https://www.r-project.org/

36. Backdash JZ, Marusich LR. rmcorr: Repeated Measures Correlation [Internet]. 2018. Available from: https://cran.r-project.org/package=rmcorr

37. Bates D, Mächler M, Bolker B, Walker S. Fitting Linear Mixed-Effects Models Using Ime4. J Stat Softw [Internet]. 2015 [cited 2019 Mar 4];67(1). Available from: http://www.jstatsoft.org/v67/i01/

38. Luke SG. Evaluating significance in linear mixed-effects models in R. Behav Res Methods [Internet]. 2017 Aug 12 [cited 2019 Mar 4];49(4):1494-502. Available from: http://link.springer.com/10.3758/s13428-016-0809-y

39. Magezi DA. Linear mixed-effects models for within-participant psychology experiments: an introductory tutorial and free, graphical user interface (LMMgui). Front Psychol [Internet]. 2015 Jan 22 [cited 2019 Mar 4];6. Available from: http://journal.frontiersin.org/article/10.3389/fpsyg.2015.00002/abstract

40. Croskerry P. The importance of cognitive errors in diagnosis and strategies to minimize them. Acad Med. 2003;78(8):775-80. 